\title{
Garlic: A brief overview of its interaction with chemical drugs
}

\section{Zohre Eftekhari ${ }^{{ }^{*}}$}

${ }^{1}$ Research \& Production Complex, Quality Control Department, Pasteur Institute of Iran, Alborz- Iran

*Correspondence to:

z_eftekhari@pasteur.ac.ir

Received: 12 June 2020

Accepted: 23 June 2020

ePublished: 23 Novamber 2020

Keywords: Allium sativum $\mathrm{L}$ Garlic, Amaryllidaceae, Drug interactions, Chemical drugs

\section{Citation:}

Eftekhari Z. Garlic: A

brief overview of its interaction with chemical drugs. Plant Biotechnol Persa 2020; 2(2): 31-32.

\section{Abstract}

Allium sativum $L$. belongs to the Amaryllidaceae family that has pronounced nutritional and medicinal properties. A. Sativum L. is a plant with different nutritional and medicinal principles. Therapeutic compounds of garlic include allele, allicin, mercaptans, polysulfides, adenosine, thioglycosides, aguins, and thiosulfinates. Despite the valuable medicinal effects that have been reported for the garlic plant, but drug interactions with chemical drugs have been reported. Garlic interacts with antihypertensive drugs, Saquinavir, hypoglycemics, general anesthetics, and anticoagulants, so associated use of garlic with mentioned chemical drugs should be used with caution to prevent drug interactions and side effects.

\section{Introduction}

In the experimental medicinal sciences, medical plants play an important role in the treatment of diseases and disorders. They are a valuable source of medicine because of their active pharmaceutical ingredients $[1,2]$. One of the most widely used medicinal plants in traditional medicine is garlic. Allium sativum L. belongs to the Amaryllidaceae family that has pronounced nutritional and medicinal properties [3]. Garlic is a widely used herbal medicine in traditional medicine. The garlic plant structure includes stem, onion with the white and slender leaves, and white and red flowers. The plant grows up to $70 \mathrm{~cm}$ in height. This plant has antimicrobial, antifungal, anticancer, lipid-lowering, anti-inflammatory, anti-atherosclerosis, antioxidant, immune system stimulant, decreasing stomach acid, meningitis, anti-parasitic, and stomach tonic effect [4-15]. Therapeutic compounds of garlic include allele, allicin, mercaptans, polysulfides, adenosine, thioglycosides, aguins, and thiosulfinates [16]. Despite the valuable medicinal effects that have been reported for the garlic, but this widely used medicinal plant may reveal interactions with chemical drugs. Different studies mentioned that garlic interacts with antihypertensive drugs that prescribe to adjustment the blood pressure. It also interacts with Saquinavir and reduces the level of the drug in the blood circulatory [17]. Additionally, garlic interacts with cholesterol-lowering and enhance the drug effect in the body [18]. Other drug interactions of garlic include increasing the possibility of hypoglycemia due to the effect on hypoglycemic drugs [19]. On the other hand, garlic interacts with general anesthetics by increasing INR, fibrinolytic activity, and platelet-activating anti-factor activity [20]. This plant interacts with anticoagulants such as heparin, warfarin, and aspirin which increases the risk of bleeding and INR [19,21-23]. 
According to various studies that have proven the drug interaction of this valuable plant with chemical drugs, so the simultaneous use of garlic with chemical drugs should be used with attentiveness to prevent different side effects.Conclusion

The results of this short review study showed that the drug G. glabra L. can interact with various chemical drugs, so the concomitant use of G. glabra L. with other drugs requires caution.

\section{Authors' contribution}

All authors contributed equally to the manuscript.

\section{Conflicts of interest}

The authors declared no competing interests.

\section{Ethical considerations}

Ethical issues (including plagiarism, data fabrica 7 tion, double publication and etc.) have been completely ob $\neg$ served by author.

\section{Funding/Support}

None.

\section{References}

1. Eftekhari Z. Antimicrobial properties of medicinal plants; The new therapeutic aspect of Valeriana officinalis. Plant Biotechnol Persa. 2020; 2 (1): 59-60.

2. Abassi N, Ghaneialvar H, Shahsavari S. Natural remedies effective on stomachache in traditional medicine. Plant Biotechnol Persa. 2020; 2 (1): 42-47.

3. Velisek J. Kubec R. Davidek J. Chemical composition and classification of culinary and pharmaceutical garlic- based products. Z Lebensem Unters Forsch. 1997; 204: 161-164.

4. Blok E. The organosulfur chemistry of the genus allium implications for the organic chemistry of sulfur. Angew Chem Int Ed Eng. 1992; 31(9): 1135-78.

5. Buates S, Matlashewski G. Treatment of experimental Leishmaniasis with the immunomodulators imiquimod and S 28463: Efficacy and mode of action. J Infect Dis. 1999; 179(6): 1485-90.

6. Ledezma E. Apitz-Castro R. Ajoene the main active compound of garlic (Allium sativum): a new antifungal agent. Rev Iberoam Micol. 2006; 23: 75-80.

7. Chung LY. The antioxidant properties of garlic compounds: allyl cysteine, alliin, allicin, and allyl disulfide. J Med Food. 2006; 9: 205-213.

8. Sumioka I. Hayama M. Shimokawa Y. Shiraishi S. Tokunaga A. Lipid-lowering effect of monascus garlic fermented extract (MGFE) in hyperlipidemic subjects. Hiroshima J Med Sci. 2006; 55: 59-64.

9. Su CC. Chen GW. Tan TW. Lin JG. Chung JG. Crude extract of garlic induced caspase-3 gene expression leading to apoptosis in human colon cancer cells. In Vivo. 2006; 20: 85-90.

10. Mayeux PR. Agrawal KC. Tou JS. King BT. Lippton HL. Hyman Al. et al. The pharmacological effects of allicin a constituent of garlic oil. Agents and pharmacological effects of allicin, a constituent of garlic oil. Agents Actions. 1988; 25: 182-190.

11. Mc Grindle BW Helden E conner WT. Garlic extract therapy in children with hypercholesterlemia. Arc pediat Adolesc
Med. 1998; 152: 1089-1094.

12. Isaacsohn JL. Moser M. stein EA. Dudley K. Davey JA. Liskov E. et al. Garlic powder and plasma lipids and lipoproteins: a multicenter, randomized, placebo-controlled trial. Arch Intern Med. 1998; 158: 1189-1194.

13. Koscienly J. Klussendorf D. Latza R. Schmitt R. Radtke H. Sieqel G. The antiatherosclerotic effect of Allium sativum. Atherosclerosis. 1999; 144: 237-249.

14. You WC. Blot WJ. Chang YS. Ershow A. Yang ZT. An Q. Allium vegetables and reduced risk of stomach cancer. J Natl Cancer Inst. 1989; 81: 162-164.

15. Sabayan B. Foroughinia F. Chohedry A. A postulated role of garlic organosulfur compounds in prevention of valproic acid hepatotoxicity. Med Hypotheses. 2007; 68: 512-514.

16. Block E. The chemistry of garlic and onions. Sci Amer. 1985; 252:14-119.

17. Brent J. Herbal drug interaction chart. http:// www.sdh.sk.ca/ rxfiles. July 2002.

18. Mills S and Bone K. Principle and practice of phytotherapy (Modern herbal medicine). Churchill Livingstone. 2000: 104-7.

19. Warber S, Bancroft J, Pedroza J. Herbal Appendix. Clinics in Family Practice. 2002; 4:1-16.

20. http://www.vitalgoods.com/myibis/herbdru g.pdf.

21. Jones BD, Runikis RM. Interaction of Ginseng with phenelzine. J. Clin. Psychopharmacol. 1987; 7: 201-202.

22. http://www.bodyandfitness.com/bodyandfit ness1.html.

23. Mills $S$ and Bone K. Principle and practice of phytotherapy (Modern herbal medicine). Churchill Livingstone. 2000: 104-7. 